ical physicists, have been reached is to nullify a great deal of the cultural value of the history of science.

The faults, however, cannot outweigh the delight which awaits the reader in the many wise comments and illuminating comparisons scattered throughout the whole book. Perhaps, when in a few years time a third version is called for, the master from whom we have all learned so much might consider the dropping of the catch-titles. These may have been justified when first introduced; but has not the time now come when a history of science should place the emphasis on wie es eigentlich gewesen?

William P. D. Wightman

\section{AGRICULTURAL RESEARCH IN INDIA}

Agriculture and Animal Husbandry in India

By Dr. M. S. Randhawa. Pp. xvi +364. (New Delhi : Indian Council of Agricultural Research, 1958.) Rs. 15.00.

Mechanical Cultivation in India

By D. A. Gadkary. Pp. ix $+147+10$ plates. (New Delhi: Indian Council of Agricultural Research, 1957.) Rs. 7.25 ; $11 s .6 d$.

A GRICULTURAL research in India is a subject A of such importance that it is scarcely an exaggeration to say that the future of the world may depend upon it. Indian scientists and the Indian Council of Agricultural Research have had quite a good record so far, though both the financial and human resources of India fall far short of the real requirements of the situation. As Dr. Randhawa freely admits, other countries faced with the problem of obtaining maximum food supply from a limited area-. Japan, Italy and Egypt-obtain yields per acre three or four times India's. If India could raise her yields to these levels she could over-feed any conceivable population she is likely to have for a very long time to come. But mere transplantation of seeds, fertilizers and methods of cultivation from, say, Japan, will not suffice. Plant breeding, as optimistic farmers have found to their cost, is a laborious task which has to be done over again for even the slightest difference in climate, and then again as new pests appear.

"Agriculture and Animal Husbandry in India" does not deal with the problems on the actual frontier of research, though the compilers are clearly aware of them. It is a compendium of information on the best strains of plants now available, cultivation requirements, expected yields, and where the seeds can be obtained. The geographical maps and statistical tables have been well done, though the chapter on irrigation is disappointingly superficial, and live. stock receive much less attention than crops.

For every scientist engaged in original agricultural research India will need perhaps a hundred men to disseminate his results, as well as the elements of agricultural science, among an uninformed people. A book like this should play a valuable part in their training, and be a useful reference book to librarians in other countries.

"Mechanical Cultivation in India" is not broad enough in its scope to constitute an economic study of the circumstances (admittedly limited) in which mechanical cultivation is now worth introducing in
India. Nor is it detailed enough to serve as an operator's handbook. It appears to have been designed more as an administrative handbook, imparting the necessary minimum of information about types of machines, and making preparations for the administrative, recording and accounting duties which will arise if mechanical implements are to be operated from governmental tractor stations.

Colin Clark

\section{INDUSTRIAL GUMS}

\section{Industrial Gums}

Polysaccharides and Their Derivatives. Edited by Roy L. Whistler and James N. BeMiller. Pp. xi +766 . (New York: Academic Press, Inc.; London : Academic Press, Inc. (London), Ltd., 1959.) 25 dollars.

R RIDGING the gap between the academic chemist $B$ and the chemical technologist is always a problem since in general their points of view differ widely. Here it has been achieved by competent academic editing of a series of chapters written mainly by industrial chemists. 'The brief 'academic' chemistry of gums included in the book does not interfere, and is indeed necessary, for the main task of present. ing detailed information of those practical applications of gums which are of particular interest to food technologists, paint and textile manufacturers, paper industrialists and pharmaceutical chemists. The current prices and potential resources of many of the gums are included. Certain gums which, as yet, have not been used widely in industry are included, together with suggestions as to their possible applications.

My minor criticisms of this book include a lack of consistency from one chapter to another in depiction of polysaccharide structures and indeed their com. plete absence in certain chapters. In the otherwise competent chapter on dextran I could find no details of the Swedish manufacture of dextran or of the use of iron complexes of dextran. The author was also unaware that the structure of the mycodextran from Aspergillus niger (p. 552) had been extensively investigated and that it had been renamed nigeran, due to its marked structural difference from normal dextrans. The more detailed formula for laminaran postulated by Peat and his colleagues could well have been included. In the chapter on agar no mention is made of its application in the now widely used agar diffusion technique. The authors of the agar article are employed by the only American company manufacturing agar, and can perhaps be forgiven for advertising the superiority of their company's product as opposed to that of the much cheaper Japanese agar. The book gives detailed coverage of the literature up to the end of 1957 with scattered references from 1958.

I can thoroughly recommend this book as essential for all technical libraries, providing as it does comprehensive references to the numerous patents on the industrial uses of gums. I am sure it will be read more widely than its title suggests, since by analogy numerous applications can be suggested for many unexploited polymers, particularly as attempts are made throughout the book to relate the physical characteristics of the gums to their chemical structure. After: editing this book, Prof. Whistler will be much sought after as an industrial consultant. S. A. BARKER 